\title{
Immune thrombocytopenia: improving quality of life and patient outcomes
}

This article was published in the following Dove Press journal: Patient Related Outcome Measures

\author{
Patrick Trotter ${ }^{1,2}$ \\ Quentin A Hill ${ }^{3}$ \\ 'Department of Surgery, University of \\ Cambridge, Cambridge, UK; ${ }^{2}$ National \\ Health Service Blood and Transplant, \\ Organ Donation and Transplant \\ Directorate, Bristol, UK; ${ }^{3}$ Department \\ of Haematology, St James's University \\ Hospital, Leeds, UK
}

\begin{abstract}
Immune thrombocytopenia (ITP) is an immune-mediated disorder characterized by a reduced platelet count and patients may develop bruising or mucosal bleeding. Since 2003, generic health-related quality of life (HRQoL) measures have been applied and ITP-specific measures developed, alongside trials of novel therapeutic agents. These have identified significant morbidity in patients with ITP, including fatigue, fear of bleeding and a negative impact on role, social and work activities. This review critically evaluates HRQoL data in adults and children with ITP. It also considers the impact of treatment and how patient-reported outcomes might be applied to care to optimize patients' quality of life.
\end{abstract}

Keywords: immune thrombocytopenia, quality of life, fatigue, eltrombopag, romiplostim, bleeding, SF-36, KIT, depression, ITP-PAQ

\section{Introduction}

Primary immune thrombocytopenia (ITP) is an autoimmune disorder characterized by isolated thrombocytopenia (peripheral blood platelet count $<100 \times 10^{9} / \mathrm{L}$ ) in the absence of other causes or disorders that may be associated with thrombocytopenia. ${ }^{1}$ ITP may also be secondary, when associated with other conditions, such as infection, immunodeficiency syndromes, systemic autoimmune disease or malignancy. There are currently no definitive clinical or laboratory parameters that can define ITP and this remains a diagnosis of exclusion after considering alternative causes of thrombocytopenia, such as liver disease, medications or bone marrow disorders. ${ }^{1,2}$ ITP typically presents with bruising and mucosal bleeding. Although many patients have no bleeding or minimal bruising, serious and sometimes fatal intracranial or gastrointestinal bleeding can occur. ${ }^{3}$ Primary ITP is a rare disorder with an age-adjusted prevalence of 9.5 per 100,000 in the USA and an incidence of 2.7 per 100,000 in northern Europe. ${ }^{4}$ In children, ITP may follow viral infection and resolve spontaneously. In contrast, ITP in adults can have a subtle onset and is usually chronic in nature. Previously, ITP was considered acute if within 6 months of diagnosis and chronic when it lasted for more than 6 months. ${ }^{5}$ The classification was changed following an international consensus meeting in 2009 into newly presenting ( $<3$ months), persistent ( $3-12$ months) and chronic ( $>12$ months) ITP. ${ }^{1}$

First-line treatment for ITP is usually steroids or intravenous immunoglobulins (IVIg). Subsequent therapy may involve immunosuppression (eg, rituximab, mycophenolate or azathioprine), surgical splenectomy or thrombopoietin receptor agonists (TPO-RAs, eg, eltrombopag or romiplostim). ${ }^{2}$ Not all patients require treatment.
Correspondence: Quentin A Hill Department of Haematology, St James's University Hospital, Beckett Street, Leeds, UK

Email quentinhill@nhs.net 
Approximately two-thirds of children with ITP recover within 6 months without specific treatment. ${ }^{6}$ In adults, treatment is usually initiated for bleeding or when the risk of serious bleeding is thought to be increased. It is generally accepted that patients with a platelet count persistently $\geq 30 \times 10^{9} / \mathrm{L}$ are not at risk of serious bleeding and can be observed, ${ }^{3,7}$ unless there are additional considerations such as elective surgery. Fortunately, many patients with a platelet count $<30 \times 10^{9} / \mathrm{L}$ never develop serious bleeding. In these patients, the decision to treat must then be individualized, based first on factors that may influence bleeding risk, such as platelet count, age, comorbidity, bleeding symptoms and lifestyle. Second, the burdens of treatment must be weighed against its benefits. For example, at a time when first-line treatment was usually oral corticosteroids followed by second-line immunosuppression, mortality from infection was found to be as great as that from bleeding. ${ }^{8,9}$ Measurement of patient-reported outcomes (PROs) is a critical method for evaluating the impact of disease and the burdens and benefits of treatment. Health-related quality of life (HRQoL) describes assessment of those areas or "domains" most affected by health technologies, including physical health (energy, fatigue, pain and sleep), psychological health (self-esteem, concentration and body image), independence (work and activities of daily living) and social relationships (sexual activity and personal relationships). As well as supporting clinical decision making, assessment of HRQoL is important for drug development. Licensing authorities such as the US Food and Drug Administration and the European Medicines Agency have issued guidance to encourage the use of validated and applicable measures of HRQoL. ${ }^{10}$

It has been over a century since Paul Kaznelson realized that increased platelet destruction in the spleen was important in the pathogenesis of ITP, leading to the first successful treatment by splenectomy in $1916 .{ }^{11}$ However, measures of HRQoL have only been applied to ITP patients since 2003. This has been driven by clinicians' desire to better understand their patients' experience, evidenced by the independent development of ITP-specific HRQoL measures, ${ }^{12}$ but also by the expansion of novel therapies for ITP, and the use and validation of HRQoL measures to support these trials. In this review, we will examine what HRQoL measures have been applied to patients with ITP as well as what we have learnt from these studies.

\section{Methods}

To review the literature, we conducted a MEDLINE search that combined the subject heading "quality of life" in titles, and a search with the subject heading "Purpura, Thrombocytopenia, Idiopathic/" as a key word. Both included all subheadings and used the explode function, but were limited to English language and human studies between 1960 and 2017. This search identified 24 papers that were then reviewed for relevance. The MEDLINE search was supplemented by a PubMed search using the key phrases "immune thrombocytopenia" and "quality of life".

\section{How HRQoL has been assessed in patients with ITP}

HRQoL is usually made quantifiable through a scored multiple-choice questionnaire that addresses the domains outlined above. Tools for this purpose should be designed in consultation with patients to better understand their priorities and more accurately capture the impact of disease on their lives. Once designed, tools need to be reassessed by new patients to ensure that the wording allows consistent understanding of the questions. Patients can also help to prioritize the most important questions, to ensure that the questionnaire is concise. The questionnaire must also be shown to be reliable (consistent and reproducible, eg, when the patients' health is stable) and valid (ie, it accurately reflects the concept that it was designed to measure). The tool should also be sufficiently responsive to detect a change in HRQoL that clinicians and patients agree is important. ${ }^{13}$ This minimal (clinically) important difference (MID) can be calculated with anchor-based or distribution-based methods and may be larger than a statistically significant change. The MID is a useful concept for classifying "responders" and interpreting differences between patients and between treatment groups. ${ }^{14}$

Generic HRQoL tools have been applied to patients with ITP. Since they have been used extensively, their properties are understood and a given score can be contextualized with scores achieved by patients with other diseases or the general population. Generic tools that have undergone validation and reliability assessment in adult patients with ITP, as well as other conditions, include the 36-Item Short-Form Health Survey (SF-36), Functional Assessment of Chronic Illness Therapy fatigue subscale (FACIT fatigue) and Functional Assessment of Cancer Therapy thrombocytopenia subscale (FACT-Th6). The generic measure Pediatric Quality of Life Inventory (PedsQL ${ }^{\mathrm{TM}}$ ) has been found to have acceptable reliability in children with ITP. ${ }^{15}$

ITP-specific tools have also been developed. These have the benefit of being able to explore disease-specific issues such as the impact of bleeding, which may increase their 
responsiveness, but small patient numbers make full validation and reliability testing harder. ${ }^{13}$ Examples include the Immune Thrombocytopenia Patient Assessment Questionnaire (ITP-PAQ) for adults, and the Kids' ITP Tools (KIT) and ITP-Quality of Life (ITP-QoL) measures for children. Because the HRQoL assessment tools and natural history of ITP differ between adults and children, they are considered separately. The key findings from HRQoL studies in adults (Table 1) and children (Table 2) are presented.

\section{HRQoL in adults with ITP Is HRQoL reduced?}

Generic HRQoL tools have objectively demonstrated clinically significant reductions in some aspects of HRQoL. Cross-sectional studies using the SF-36 have shown worse HRQoL in patients with ITP compared to the general population. Although a formal calculation of MID in patients with ITP using SF-36 has not been carried out, a recent crosssectional study comparing patients with ITP to controls estimated the MID to be 8 points on a $0-100$ scale, based on previous studies. ${ }^{16}$ Patients with ITP had lower HRQoL that exceeded the MID in two out of eight domains. The domains were "role physical", limitations in work or other common activities due to physical problems; and "role emotional", limitations due to emotional problems. Other studies using SF-36 have also found lower HRQoL in ITP patients vs controls. One found a statistically significant reduction in six out of eight domains. ${ }^{17}$ The three domains with greater than 8 points were again role physical and role emotional, as well as social functioning. A further study found a significant reduction in seven out of eight domains, all $\geq 8$ points. ${ }^{18} \mathrm{~A}$ significant reduction in seven out of eight domains was also found in another study. ${ }^{19}$ Although the differences were less than 8 points in the latter study, $44 \%$ of patients with ITP had a normal platelet count at the time of the survey. One study compared HRQoL in ITP to those with other chronic conditions, finding significantly worse physical (but not mental) component scores in patients with ITP vs those with arthritis and cancer. ${ }^{18}$

\section{When is HRQoL reduced?}

Epidemiological studies found ITP patients had a higher occurrence of comorbid diseases such as diabetes, renal failure, vascular events and infections before their ITP diagnosis compared with non-ITP individuals..$^{20}$ In the year before their initial ITP diagnosis, those with chronic ITP took more medications used to treat pain conditions and vitamin deficiencies, compared with the general population. ${ }^{20}$ Whether this relates to comorbid disease or reflects early symptoms related to ITP is unknown.

With the current standard of care, HRQoL appears to deteriorate in the first year after diagnosis. A cross-sectional study found that HRQoL was worse after 6 months vs within 6 months of diagnosis. ${ }^{17}$ Another found HRQoL to be worse in those with persistent ITP (3-12 months from diagnosis) compared with those who had been diagnosed for less than 3 months or greater than 12 months. ${ }^{16}$ Other studies found that HRQoL tended to improve later in the disease course. For example, one study found that HRQoL was better in patients at least 5 years from diagnosis vs within 5 years. ${ }^{19}$ In two longitudinal studies of 6 months' duration, studying patients diagnosed at least 6 months previously, the placebo arms did not show improvement in HRQoL. ${ }^{21,22}$ However, a longer study of patients with chronic ITP found improvement in HRQoL from baseline to 52 weeks in patients receiving standard of care. ${ }^{23}$ This study used the ITP-PAQ, an ITPspecific measure developed by Amgen to support trials of the TPO-RA romiplostim. Whether it will become available for wider use is unclear, but it has shown acceptable validity and reliability. ${ }^{24,25}$ ITP-PAQ scales are on a 0 (worst) to 100 continuum and MID estimates have been made for nine out of eleven scores (10-15 points for two and 8-12 for seven). ${ }^{14}$ The improvement from baseline to 52 weeks in patients receiving standard of care exceeded the MID in four out of seven scales assessed. ${ }^{23}$ Taken together, these studies suggest that HRQoL tends to worsen during the first year after diagnosis, but subsequently improves.

\section{How is HRQoL reduced?}

Mathias et $\mathrm{al}^{26}$ developed a conceptual model of the impact of ITP on HRQoL (Figure 1) based on a literature review which identified key HRQoL issues that were then explored with three focus groups totaling 23 patients. This model describes how both disease and its treatment lead to symptoms and treatment side effects that impact on multiple domains of HRQoL. A limitation of this model is that thrombocytopenia may not be the sole driver of symptoms in ITP. For example, the degree of fatigue may, at least in part, be driven by the underlying immune dysregulation and be the result of complex interactions among premorbid factors, including comorbidity, social circumstances and illness beliefs, as well as disease and its treatment (Figure 2).

In the studies discussed above, adult patients found the negative impact of ITP on role and social activities to be particularly bothersome, ${ }^{16,17}$ and further studies support these findings. In group discussion, patients reported limitations 
Table I Studies of HRQoL in adults with ITP

\begin{tabular}{|c|c|c|c|c|}
\hline Study & $\begin{array}{l}\text { Assessment } \\
\text { tool(s) }\end{array}$ & Population & Analysis & $\begin{array}{l}\text { Use of } \\
\text { MID }\end{array}$ \\
\hline Zhou $2007^{17}$ & $\begin{array}{l}\text { SF-36 (Chinese } \\
\text { mainland version) }\end{array}$ & 236 adults with ITP & $\begin{array}{l}\text { Cross-sectional study. HRQoL compared with } \\
\text { a survey of } \mathrm{I}, 688 \text { healthy individuals. Also asked } \\
\text { about fear of bleeding }\end{array}$ & No \\
\hline Bussel $2007^{42}$ & SF-36v2 & $\begin{array}{l}\text { Trial of II8 adults with chronic } \\
\text { ITP randomized to eltrombopag or } \\
\text { placebo }\end{array}$ & $\begin{array}{l}\text { Evaluation of impact of treatment on HRQoL as } \\
\text { a secondary endpoint }\end{array}$ & No \\
\hline Mathias $2007^{24}$ & ITP-PAQ & 73 adult patients with ITP & $\begin{array}{l}\text { Development and validation of the ITP-PAQ. } \\
\text { Administered twice }\end{array}$ & No \\
\hline Mathias $2007^{25}$ & ITP-PAQ & $\begin{array}{l}34 \text { adult patients with chronic ITP } \\
\text { receiving romiplostim in an open-label } \\
\text { trial }\end{array}$ & $\begin{array}{l}\text { Assessment of responsiveness, reliability and } \\
\text { validity of the ITP-PAQ. Administered at baseline } \\
\text { and weeks } 4,12 \text { and } 24 \text {. }\end{array}$ & No \\
\hline $\begin{array}{l}\text { McMillan } \\
2008^{18}\end{array}$ & SF-36 & 73 adult patients with chronic ITP & $\begin{array}{l}\text { Evaluation of HRQoL in ITP patients compared } \\
\text { with the general US population and six other } \\
\text { common disorders. Consenting patients } \\
\text { completed the survey then repeated it } 2 \text { weeks } \\
\text { later }\end{array}$ & No \\
\hline Snyder $2008^{19}$ & $\begin{array}{l}\text { ITP-PAQ, SF-36 and } \\
\text { EQ-5D }\end{array}$ & $\begin{array}{l}\text { Cross-sectional web-based survey } \\
\text { of I,002 adult ITP patients and I,03I } \\
\text { controls }\end{array}$ & $\begin{array}{l}\text { SF-36 and EQ-5D scores in ITP patients } \\
\text { compared with controls. The impact of } \\
\text { splenectomy status, duration of illness and } \\
\text { platelet count on HRQoL was assessed in ITP } \\
\text { patients }\end{array}$ & No \\
\hline Mathias $2009^{14}$ & ITP-PAQ & $\begin{array}{l}\text { I25 adults with chronic ITP } \\
\text { participating in two randomized } \\
\text { placebo-controlled trials of } \\
\text { romiplostim }\end{array}$ & $\begin{array}{l}\text { Estimation of the MID for 9/II ITP-PAQ scores } \\
\text { using a combination of anchor and distribution- } \\
\text { based methods }\end{array}$ & Yes \\
\hline George $2009^{22}$ & ITP-PAQ & $\begin{array}{l}\text { I25 adults with chronic ITP } \\
\text { participating in two randomized } \\
\text { placebo-controlled trials of } \\
\text { romiplostim }\end{array}$ & $\begin{array}{l}\text { Comparison of HRQoL in ITP patients receiving } \\
\text { romiplostim vs placebo. ITP-PAQ was self- } \\
\text { administered at baseline and weeks } 4,12 \text { and } 24\end{array}$ & No \\
\hline Newton 20I I35 & FIS & $\begin{array}{l}585 \text { adults (UK), } 93 \text { adults (USA) with } \\
\text { active ITP or a prior history of ITP }\end{array}$ & $\begin{array}{l}\text { Comparison of fatigue in ITP patients with } \\
\text { normal subjects. Multivariate analysis of patient } \\
\text { characteristics associated with fatigue }\end{array}$ & No \\
\hline
\end{tabular}




\begin{tabular}{|c|c|}
\hline $\begin{array}{l}\text { Reliability and validity } \\
\text { assessment }\end{array}$ & Findings \\
\hline $\begin{array}{l}\text { No. Tested in other medical } \\
\text { conditions, including hemophilia, } \\
\text { another bleeding disorder }\end{array}$ & $\begin{array}{l}\text { In } 6 / 8 \text { SF-36 subscores (dimensions), HRQoL was significantly worse in patients with ITP vs healthy } \\
\text { individuals (not energy/vitality). Significantly worse HRQoL was found in } 3 \text { domains for those with a lower } \\
\text { platelet count and chronic vs acute ITP. In regression analysis, treatment cost, increasing age and fear of } \\
\text { bleeding were predictors of worse HRQoL }\end{array}$ \\
\hline No & $\begin{array}{l}\text { HRQoL by SF-36v2 was similar at baseline and end of study. There was a significant decrease from baseline in } \\
\text { the mean emotional-role score for the group receiving } 75 \mathrm{mg} \text { of eltrombopag }\end{array}$ \\
\hline Yes & $\begin{array}{l}\text { Test-retest reliability judged acceptable. Internal consistency reliability, measured by Cronbach's alpha was } \\
\text { acceptable for all scales except reproductive health. Construct validity was demonstrated by moderate to } \\
\text { strong correlation between ITP-PAQ and SF- } 36 \text { and CES-D scores with the exception of the reproductive } \\
\text { health scale. In known groups validity testing, a significant difference was identified between those on } \\
\text { treatment vs those who were not }\end{array}$ \\
\hline Yes & $\begin{array}{l}\text { 5/I0 of the ITP-PAQ scales were sensitive to clinical (platelet) response. Internal consistency reliability and } \\
\text { test-retest reliability were acceptable for most scales. Construct validity was supported by correlation } \\
\text { between ITP-PAQ and SF- } 36 \text { scales with the exception of menstrual symptoms and fertility subscales. In } \\
\text { known groups validity testing, durable platelet responders had significantly better scores than nonresponders } \\
\text { for symptoms, bother, psychological and overall QoL scales }\end{array}$ \\
\hline $\begin{array}{l}\text { Reliability assessed in ITP } \\
\text { population. Found acceptable } \\
\text { internal reliability (Cronbach's } \\
\text { alphas) and test-retest reliability }\end{array}$ & $\begin{array}{l}\text { Scores of ITP patients were lower than the US general population in all } 8 \text { domains and both summary scores } \\
\text { (statistically significant in all except mental health). ITP patients on active treatment had significantly lower } \\
\text { scores in } 6 / 8 \text { domains vs those not receiving treatment. When ITP patients were compared with other } \\
\text { medical conditions, physical but not mental component scores were significantly worse than in patients with } \\
\text { hypertension, arthritis or cancer (not controlled for disease severity) }\end{array}$ \\
\hline No & $\begin{array}{l}\text { Significantly worse scores in ITP patients on 7/8 SF-36 domains (not bodily pain), SF-36 physical and mental } \\
\text { summary scores, and on the EQ-5D visual analog scale vs controls. SF- } 36 \text { and EQ-5D scores not significantly } \\
\text { different in ITP patients who had undergone splenectomy vs those that had not, but they scored significantly } \\
\text { worse on } 5 / 10 \text { ITP-PAQ scales. On the ITP-PAQ, patients diagnosed within the past } 5 \text { years had worse } \\
\text { bother and overall QoL scores than less recently diagnosed patients. A lower platelet count was consistently } \\
\text { associated with worse ITP-PAQ scores and had weaker associations with SF-36 and EQ-5D scores. } \\
\text { Differences between ITP patients and controls were noted to be generally small, despite their statistical } \\
\text { significance. Also noted that ITP group generally well controlled and } 44 \% \text { had platelet counts }>150 \times 10^{9} / \mathrm{L}\end{array}$ \\
\hline No & $\begin{array}{l}\text { Each ITP-PAQ scale had all its item scores transformed to a } 0 \text { (worst) to I00 (best) continuum. MIDs ranged } \\
\text { from } 8 \text { to I } 2 \text { points for symptoms, bother, psychological, overall QoL, social activity, menstrual symptoms } \\
\text { and fertility. MID was } 10-15 \text { points for the fatigue and activity scales. Recommended further work to finalize } \\
\text { these estimates }\end{array}$ \\
\hline No & $\begin{array}{l}\text { In patients receiving placebo, } 0 / 10 \text { ITP-PAQ scales improved between baseline and } 24 \text { weeks. Patients } \\
\text { receiving romiplostim had statistically significant improvements over placebo in } 4 / 10 \text { ITP-PAQ scales } \\
\text { (splenectomized patients) and } 1 / 10 \text { scales (nonsplenectomized). A post-hoc pooled analysis found statistically } \\
\text { significant improvement in } 7 / 10 \text { scales. No analysis found a difference in the fatigue scale between treatment } \\
\text { and placebo. Significantly better scores were associated with a durable platelet count response in } 2 / 10 \text { scales } \\
\text { (bother and psychological health). At baseline, splenectomized patients had significantly lower scores in } 7 / 10 \\
\text { scales vs nonsplenectomized patients }\end{array}$ \\
\hline $\begin{array}{l}\text { Validated in other fatigue- } \\
\text { associated diseases (PBC, CFS). } \\
\text { In a prior study, } 40 \text { normal adults } \\
\text { had a mean FIS score of } 13 \text {. } \\
\text { Assuming a normal distribution } \\
\text { and that the patients were } \\
\text { representative of the normal } \\
\text { population, } 2.5 \% \text { of the normal } \\
\text { population would be expected to } \\
\text { have a fatigue score } \geq 40 \text { ( } 2 \text { SD } \\
\text { above the mean) }\end{array}$ & $\begin{array}{l}\text { Significantly more patients in the UK cohort }(39 \%) \text { and US cohort }(22 \%) \text { had fatigue compared to normal } \\
\text { subjects }(P<0.000 \mathrm{I} \text { in both groups). In multivariate analysis, for patients with bleeding symptoms, fatigue } \\
\text { was associated with a platelet count }<100 \times 10^{9} / \mathrm{L} \text { and female gender. In patients without bleeding symptoms, } \\
\text { fatigue was associated with a platelet count }<30 \times 10^{9} / \mathrm{L} \text {, presence of other medical conditions, daytime } \\
\text { sleepiness and orthostatic symptoms. Fatigue was not associated with duration of ITP or splenectomy status }\end{array}$ \\
\hline
\end{tabular}


Table I (Continued)

\begin{tabular}{|c|c|c|c|c|}
\hline Study & $\begin{array}{l}\text { Assessment } \\
\text { tool(s) }\end{array}$ & Population & Analysis & $\begin{array}{l}\text { Use of } \\
\text { MID }\end{array}$ \\
\hline Cheng 20I $\mathrm{I}^{21}$ & $\begin{array}{l}\text { SF-36v2, FACIT } \\
\text { fatigue subscale, } \\
\text { FACT-Th6 and } \\
\text { MEI-SF }\end{array}$ & $\begin{array}{l}\text { I } 97 \text { adults with chronic ITP } \\
\text { randomized to eltrombopag or } \\
\text { placebo (RAISE trial) }\end{array}$ & $\begin{array}{l}\text { HRQoL was assessed at baseline and weeks } 6 \text {, } \\
14 \text { and } 26 \text { or at discontinuation of study drug. } \\
\text { Assessment of change in HRQoL from baseline, } \\
\text { difference in HRQoL between treatment arms } \\
\text { and association between HRQoL and bleeding } \\
\text { symptoms or platelet count }\end{array}$ & No \\
\hline $\begin{array}{l}\text { Signorovitch } \\
2011^{166}\end{array}$ & $\begin{array}{l}\text { SF-36v2, FACIT } \\
\text { fatigue subscale and } \\
\text { FACT-Th6 }\end{array}$ & $\begin{array}{l}\text { Patients from two eltrombopag trials: } \\
\text { a placebo-controlled RCT (RAISE, } \\
\mathrm{n}=197) \text { and an open-label extension } \\
\text { (EXTEND, } \mathrm{n}=154 \text { ) }\end{array}$ & $\begin{array}{l}\text { Assessment of the reliability and validity of these } \\
\text { HRQoL scales in adult patients with chronic ITP }\end{array}$ & No \\
\hline Kuter $2012^{23}$ & ITP-PAQ & $\begin{array}{l}234 \text { adult nonsplenectomized ITP } \\
\text { patients in a randomized open-label } \\
52 \text {-week study of romiplostim vs SOC }\end{array}$ & $\begin{array}{l}\text { Comparison of HRQoL changes in both } \\
\text { treatment groups and by responder status and } \\
\text { splenectomy status, and after rituximab }\end{array}$ & Yes \\
\hline Efficace $2016^{16}$ & SF-36 and MFS & 424 adults with primary ITP & $\begin{array}{l}\text { Cross-sectional study comparing HRQoL and } \\
\text { fatigue with the general population and by disease } \\
\text { phase (newly diagnosed, persistent and chronic) }\end{array}$ & Yes \\
\hline
\end{tabular}

Abbreviations: CES-D, Center for Epidemiologic Studies Depression Scale; CFS, chronic fatigue syndrome; EQ-5D, Euro-Qol 5 Dimensions; FACIT, Functional Assessment of Chronic Illness Therapy; FACT-Th6, Functional Assessment of Cancer Therapy thrombocytopenia subscale; FIS, Fatigue Impact Score; HRQoL, health-related quality of life; ITP, immune thrombocytopenia; ITP-PAQ, ITP Patient Assessment Questionnaire; MEI-SF, Motivation and Energy Inventory Short Form; MFS, Multidimensional Fatigue Score; MID, minimal important difference; PBC, primary biliary cirrhosis; QoL, quality of life; RCT, randomized controlled trial; SF-36, 36-Item Short Form Health Survey; SF-36v2, 36-Item Short Form Health Survey version 2; SOC, standard of care.

in their social and leisure activities. For example, social embarrassment due to visible signs of bruising, eg, "I've had co-workers and friends ask me if my husband was beating me", led to restricted social engagement, "Well, I find myself more reluctant about meeting new people because I have so many bruises so often". ${ }^{26}$ One study found better HRQoL in patients with a lower bleeding score. ${ }^{21} \mathrm{~A}$ British patient survey identified gender differences with regard to suspicion of physical violence (women $7.1 \%$ vs men $1.6 \%$, $P=0.001$ ) and efforts at bruise concealment (women $13.5 \%$ vs men $3.2 \%, P<0.001) .{ }^{27}$ For some, fatigue and lack of energy also limited social activities, and patients reported a reduction in long-distance travel. ${ }^{26}$ Another important social issue identified was a negative impact on sexual activity through reduced libido in both genders, and bruising and bleeding during intercourse, particularly in women. While fatigue and social embarrassment may negatively impact on sporting activities, clinicians also advise sport restriction to manage bleeding risk. Activity restriction is a particular issue for children, ${ }^{28}$ and the clinical advice given to patients is not consistent. ${ }^{29}$

It is easy to imagine from the above observations that fear of bleeding could negatively impact on role and social activities, and in one study, $31 \%$ of patients with a platelet count $<10 \times 10^{9} / \mathrm{L}$ were very worried about serious bleeding. ${ }^{30}$ This fearfulness would not be identified directly by generic HRQoL tools, but has been shown to have a negative impact on HRQoL when asked about specifically. ${ }^{17,31}$ Fear of bleeding is one of the greatest issues for adult carers of children with ITP and, despite not suffering directly from the disease or treatment side effects, the carers' HRQoL scores are lower than those of the children. ${ }^{32}$ 


\begin{tabular}{|c|c|}
\hline $\begin{array}{l}\text { Reliability and validity } \\
\text { assessment }\end{array}$ & Findings \\
\hline No & $\begin{array}{l}\text { No HRQoL improvement from baseline in placebo arm. Statistically significant improvement from baseline in } \\
\text { eltrombopag arm for FACT-Th6 and SF-36v2 ( } 2 / 2 \text { summary scores and } 5 / 8 \text { domains). Statistically significant } \\
\text { greater improvement from baseline for the eltrombopag arm vs placebo was seen in FACT-Th6 and SF-36v2 } \\
\text { (I/2 summary scores and } 3 / 8 \text { domains) but not MEI-SF and FACIT fatigue subscale. Increased platelet count } \\
\text { and reduced WHO bleeding score were associated with statistically significant improvements in HRQoL }\end{array}$ \\
\hline Yes & $\begin{array}{l}\text { Acceptable internal consistency reliability, with all Cronbach's alphas }>0.70 \text {. Acceptable test-retest reliability, } \\
\text { with all intraclass correlation coefficients }>0.70 \text {. Construct validity was supported by moderate }(0.35<r<0.50) \\
\text { to strong }(r>0.50) \text { intermeasure correlations for baseline and change scores. The mean FACIT fatigue } \\
\text { score at baseline in RAISE was not significantly lower than the reference value reported for the general US } \\
\text { population }(<\mid \text { SD). Both mean summary scores and } 7 / 8 \text { domains of the SF-36v2 were within I SD of the US } \\
\text { population standardized mean }\end{array}$ \\
\hline No & $\begin{array}{l}\text { Over } 52 \text { weeks, statistically significant improvements in HRQoL occurred in both romiplostim and SOC } \\
\text { arms for } 9 / 10 \text { ITP-PAQ scales. MID estimates were available for } 7 \text { scales and the improvement from baseline } \\
\text { exceeded the MID in both arms, for } 4 / 7 \text { scales for SOC and for romiplostim only in a further } 2 / 7 \text {. No } \\
\text { significant improvement in fatigue was found in either arm. On comparing the change in scores between } \\
\text { arms, statistically significant improvements in HRQoL in those receiving romiplostim vs SOC were found in } \\
7 / 10 \text { scales but in no scale did this exceed the MID. Receiving rituximab or splenectomy did not influence } \\
\text { HRQoL but numbers were small ( } n=16 \text { and } 13 \text {, respectively). Statistically significant improvement was seen } \\
\text { in } 8 / 10 \text { scales in responders vs nonresponders regardless of treatment group. HRQoL improvements seen in } \\
\text { responders exceeded the MID for most scales, including fatigue }\end{array}$ \\
\hline No & $\begin{array}{l}\text { SF- } 36 \text { scores ranged from } 0 \text { (worst) to I00 (best) and the MID was set at } 8 \text { points based on previous studies. } \\
\text { Compared with the normal population, ITP patients had lower HRQoL that was clinically significant in } 2 / 8 \\
\text { domains of SF-36. When analyzed by disease phase, those with persistent ITP ( } 3-12 \text { months) had the worst } \\
\text { HRQoL, with reductions reaching MID in } 5 / 8 \text { domains. With MFS, ITP patients had significantly worse } \\
\text { fatigue than normal controls }(P<0.00 I) \text {. The greatest burden of fatigue occurred in those with persistent ITP. } \\
\text { Greater fatigue by MFS was associated with worse mental and physical HRQoL, especially limitation in daily } \\
\text { activity due to physical problems. Only weak correlations were found between general fatigue and platelet } \\
\text { count or bleeding score }\end{array}$ \\
\hline
\end{tabular}

In the study of Mathias et al, ${ }^{26}$ the majority of patients (87\%) found that ITP had hindered their ability to work, for example, their career advancement, productivity and need for absences, or had changed their attitude to work. A further study of 1,002 patients with ITP vs 1,031 controls confirmed this observation, finding that patients with ITP had significantly worse work productivity, more medical review and, in the preceding week, had taken more sick leave (56\% vs $30 \%$ ) and missed more chore hours (18\% vs $13 \%)$ $(P \leq 0.003) .{ }^{33}$ In the British survey, $12.5 \%$ of all patients with primary ITP reported "always" or "often" missing work or school as a result of fatigue. ${ }^{27}$

Fatigue was commonly reported by two of the three focus groups. Other studies suggest that fatigue is an issue for $22 \%-45 \%$ of patients with ITP $^{34-36}$ and fatigue scores have been found to be significantly worse than in controls. ${ }^{16,35}$ Sleep disturbance, anxiety, depression and fear were frequently mentioned by the focus groups. For example, "The worst part about it is the emotional strain that was put on everyone around me." In another study, $29 \%$ of patients experienced anxiety or depression. ${ }^{36}$

Platelet count is a commonly used proxy for disease severity and lower platelet counts have been associated with lower HRQoL. ${ }^{17,19,21}$ However, these reports do not allow conclusions to be drawn on the relative contribution of disease vs treatment. A further study of 491 patients with ITP without bleeding symptoms found, in a multivariate analysis, that greater fatigue was independently associated with a platelet count $<30 \times 10^{9} / \mathrm{L}$, but not with treatment. ${ }^{35}$

Perhaps the findings above should not be surprising. The overlapping comorbidities of depression, sleep disturbance and fatigue are often seen together in patients with cancer and chronic diseases, probably driven by immune activation and proinflammatory processes. ${ }^{37}$ It has also been shown in patients with immune-mediated inflammatory diseases that depression symptoms, anxiety symptoms and fatigue 


\begin{tabular}{|c|c|c|c|c|c|c|c|}
\hline 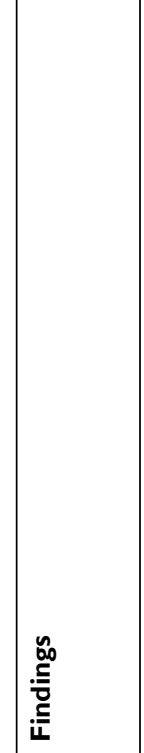 & 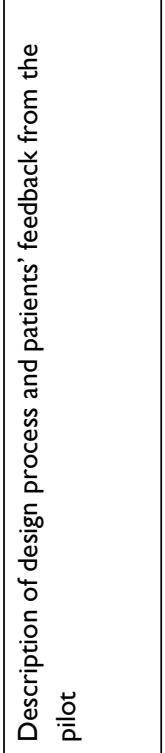 & 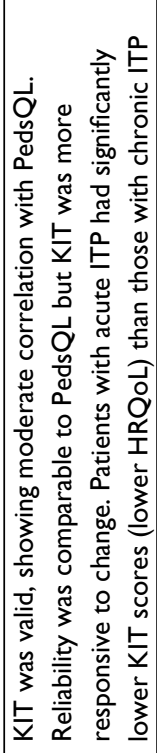 & 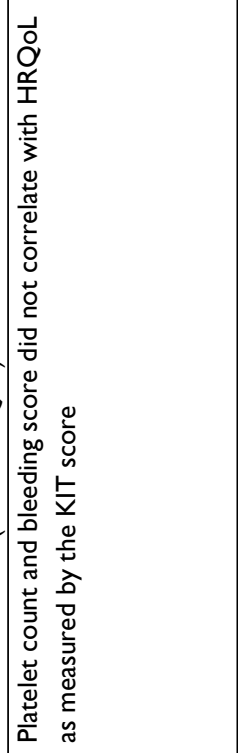 & 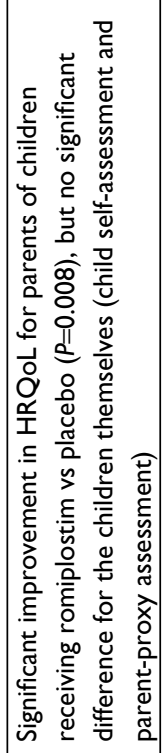 & 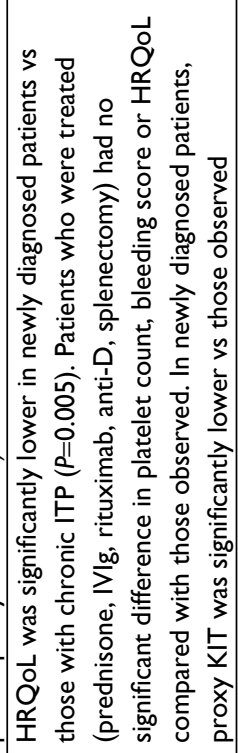 & 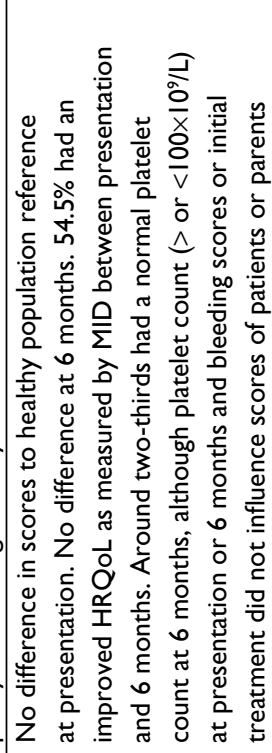 & 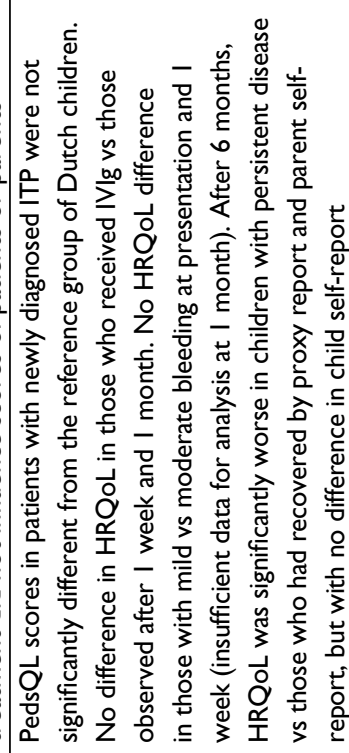 \\
\hline 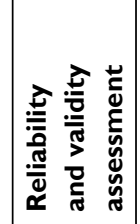 & & 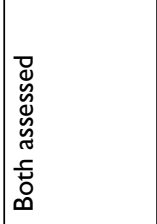 & 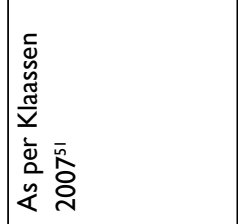 & 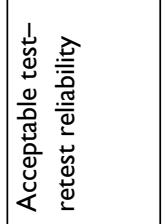 & 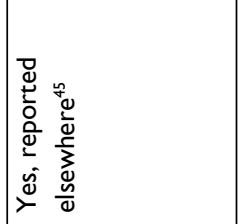 & 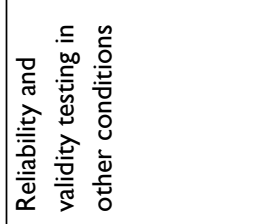 & 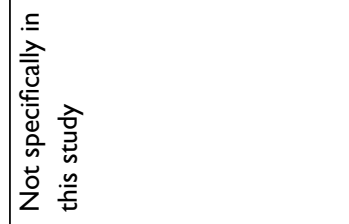 \\
\hline 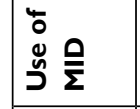 & z & z & z & ż & z & $\stackrel{y}{\check{\nu}}$ & ż \\
\hline $\begin{array}{l}\frac{n}{\frac{n}{n}} \\
\frac{\pi}{\frac{\pi}{2}} \\
\frac{\tilde{\alpha}}{4}\end{array}$ & 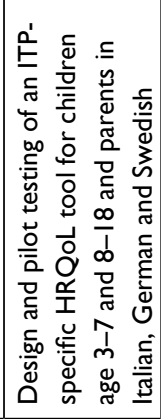 & 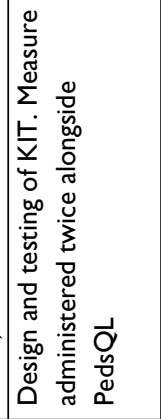 & 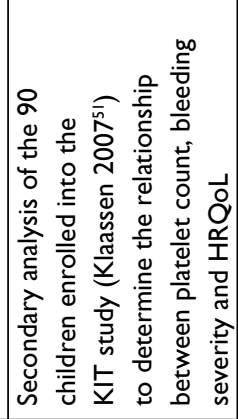 & 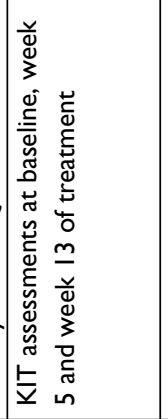 & 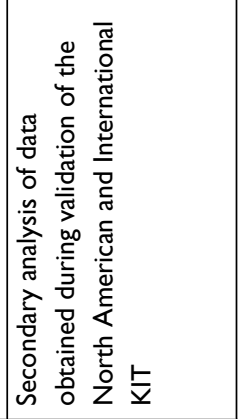 & 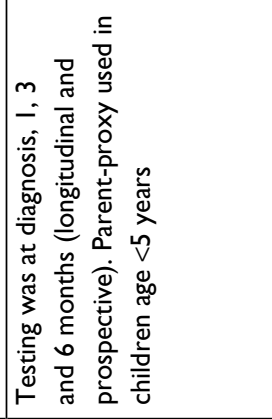 & 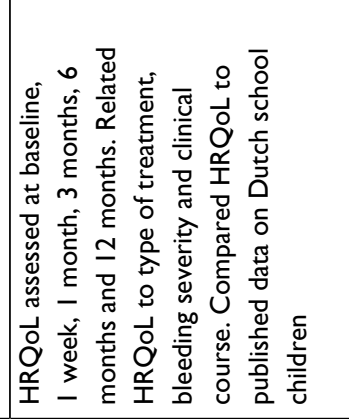 \\
\hline 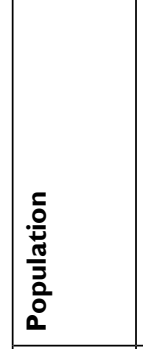 & 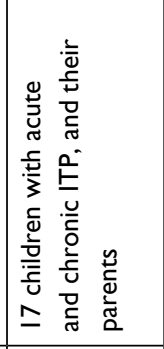 & 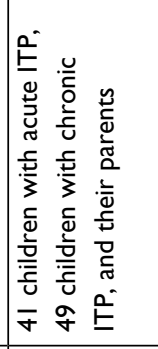 & 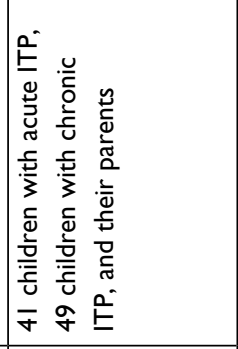 & 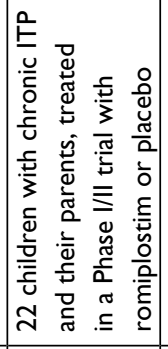 & 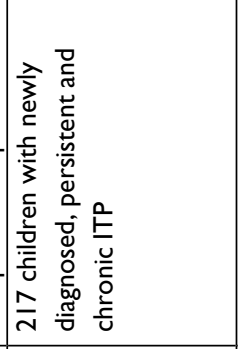 & 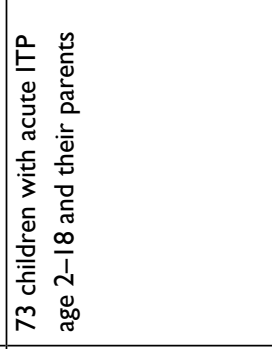 & 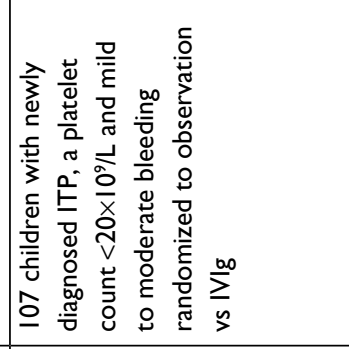 \\
\hline 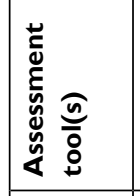 & & 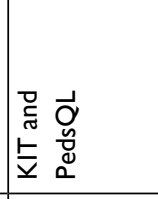 & $\overline{\mathbf{x}}$ & $\overline{\bar{x}}$ & $\overline{\mathbf{v}}$ & 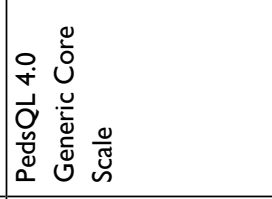 & 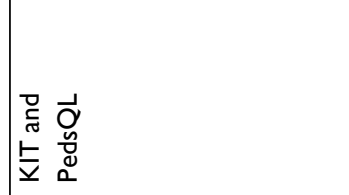 \\
\hline 苞 & 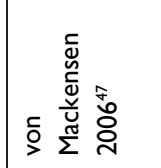 & 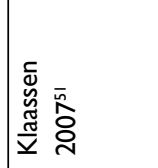 & 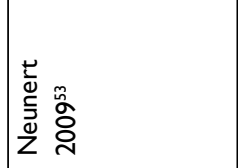 & 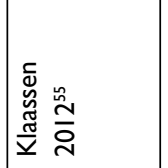 & 产总 & 竧 & 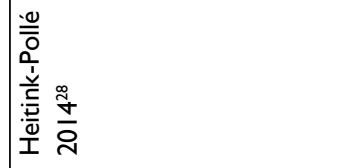 \\
\hline
\end{tabular}




\begin{tabular}{|c|c|c|c|}
\hline 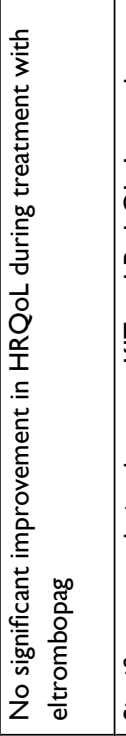 & 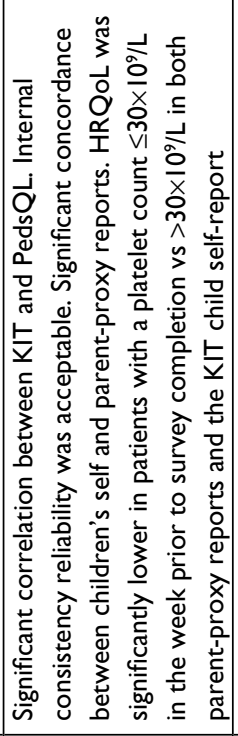 & 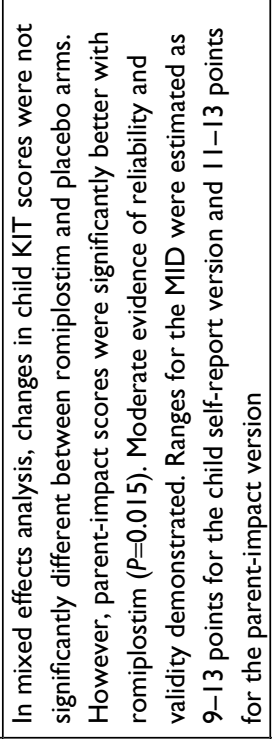 & 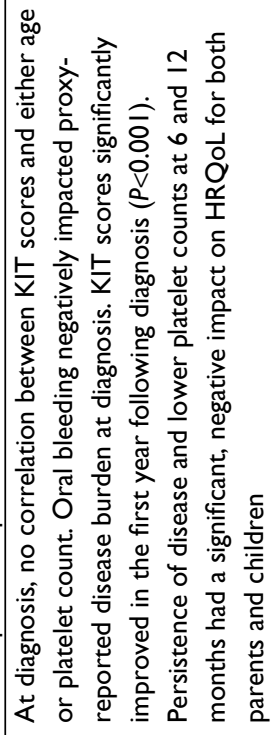 \\
\hline$\stackrel{\circ}{z}$ & 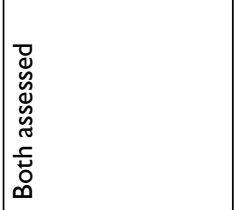 & 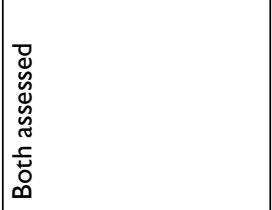 & 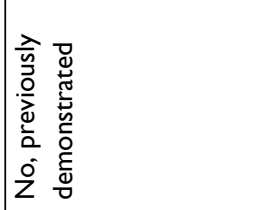 \\
\hline$\stackrel{y}{\succ}$ & 을 & $\stackrel{\ddot{\nu}}{\succ}$ & 울 \\
\hline 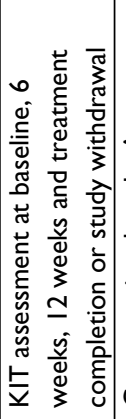 & 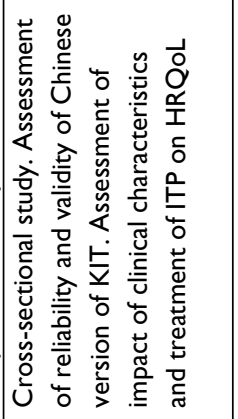 & 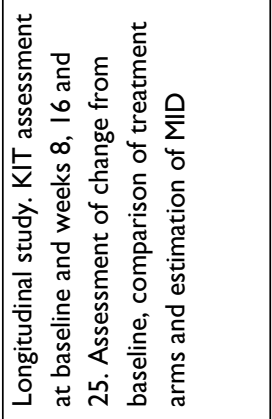 & 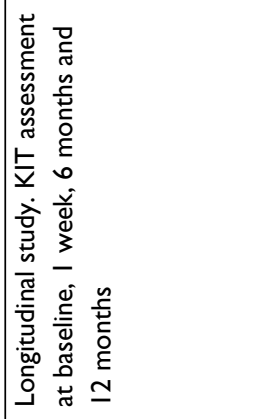 \\
\hline 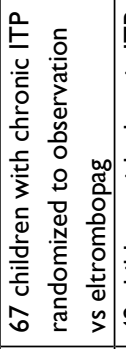 & 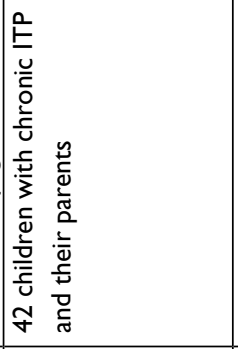 & 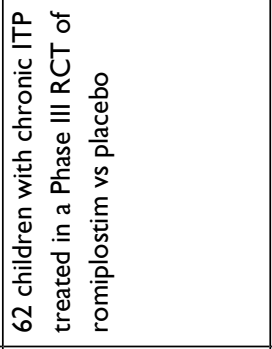 & 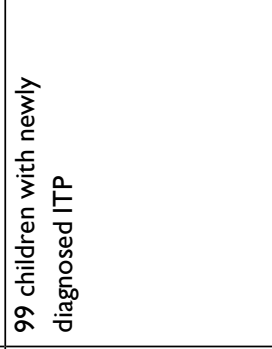 \\
\hline$\overline{\bar{x}}$ & 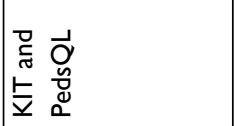 & 言 & $\overline{\bar{y}}$ \\
\hline 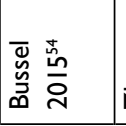 & 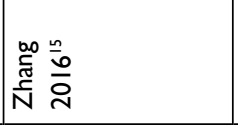 & 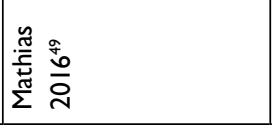 & 递 $\frac{\tilde{\pi}}{2}$ \\
\hline
\end{tabular}




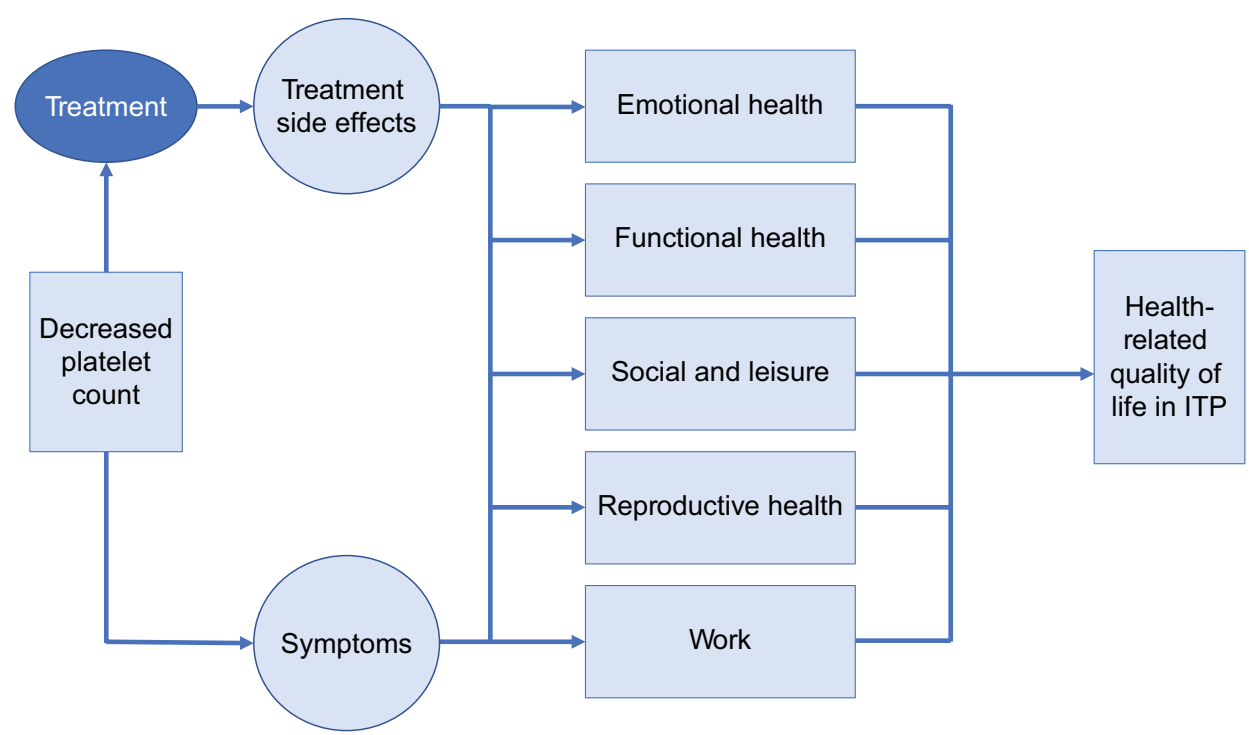

Figure I Conceptual model for health-related quality of life in patients with ITP.

Note: Reproduced from Mathias SD, Gao SK, Miller KL, et al. Impact of chronic Immune Thrombocytopenic Purpura (ITP) on health-related quality of life: a conceptual model starting with the patient perspective. Health Qual Life Outcomes. 2008;6:13. Creative Commons license and disclaimer available from: http://creativecommons.org/ licenses/by/4.0/legalcode. ${ }^{26}$

Abbreviation: ITP, immune thrombocytopenia.

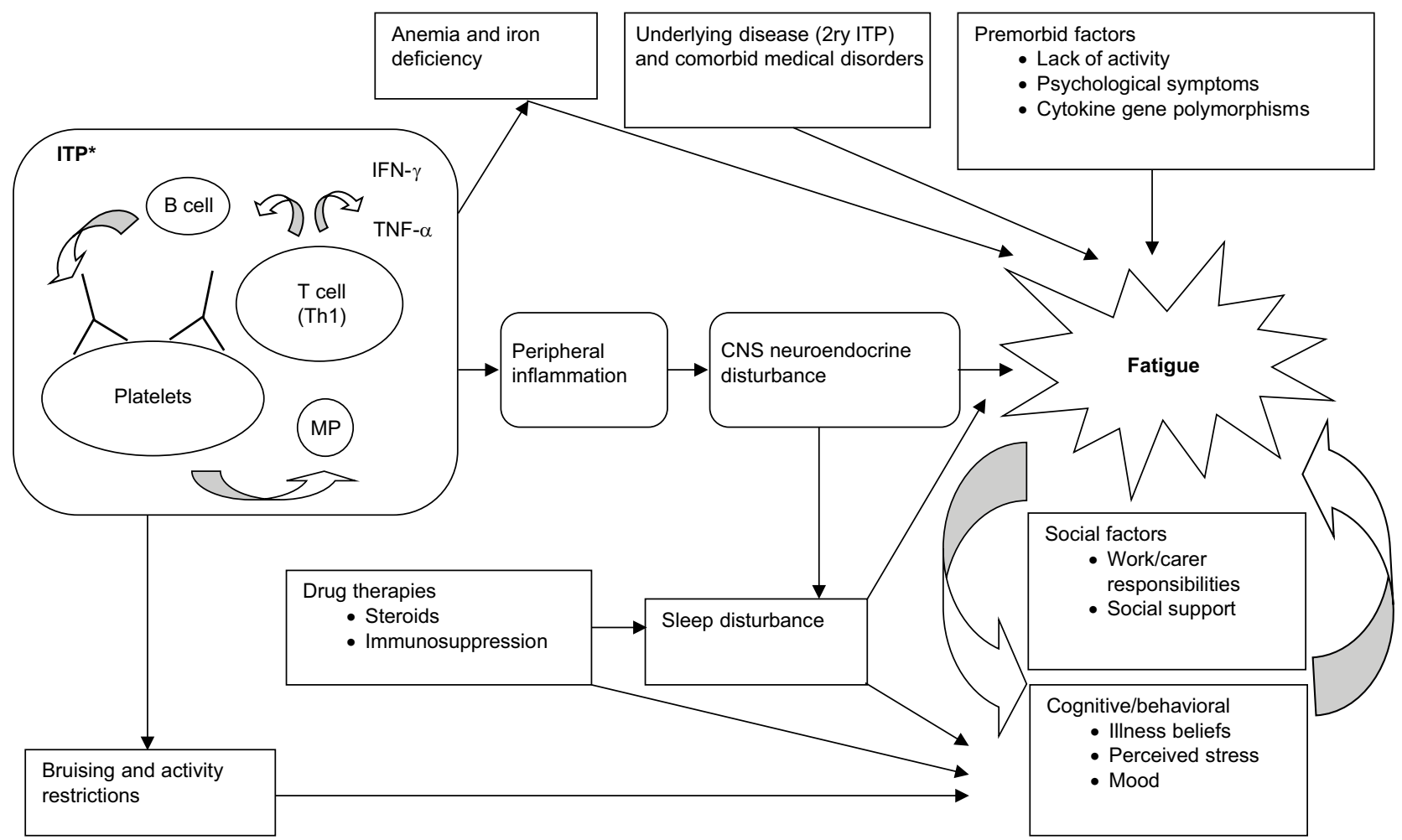

Figure 2 Model of the pathogenesis of ITP-associated fatigue.

Notes: *T cells can attack platelets directly, secrete proinflammatory cytokines and drive formation of autoreactive B cells. This results in antibody- and complementmediated platelet destruction. Platelet microparticles are prothrombotic and able to activate the proinflammatory complement pathway. Reproduced from Hill QA, Newland AC. Fatigue in immune thrombocytopenia. Br J Haematol. 2015;170(2):14I-149 with permission from the publisher, John Wiley and Sons. @ 2015 John Wiley \& Sons Ltd. ${ }^{37}$ Abbreviations: ITP, immune thrombocytopenia; 2ry, secondary; B cell, autoantibody producing B lymphocytes; T cell (ThI), T lymphocyte with a T helper I polarization; TNF- $\alpha$, tumor necrosis factor- $\alpha$; IFN- $\gamma$, interferon- $\gamma$; MP, microparticle; CNS, central nervous system. 
individually show significant associations with work absenteeism and general activity impairment. ${ }^{38}$ Similar associations were found in a cross-sectional study of 111 adults with chronic ITP that assessed fear of bleeding, anxiety and depression by Hamilton rating scales and HRQoL by the SF-36. ${ }^{31}$ Thirty-five percent had moderate to severe fear of bleeding, $37 \%$ had moderate to very severe depression and $21 \%$ were anxious. Fear of bleeding was significantly associated with anxiety and depression scores $(P<0.05)$. Higher anxiety and depression scores had significant negative associations with all domains of the SF-36 $(P<0.001)$.

\section{How does treatment influence HRQoL?}

The burdens of treatment such as hospital attendance and side effects will negatively influence HRQoL, but effective treatment should have the reverse effect. Hence, although HRQoL has been found to be worse in ITP patients on active treatment, ${ }^{18}$ this does not show causality, only that patients with a greater disease burden requiring treatment have worse HRQoL.

\section{Steroids}

Patients find the side effects of steroids particularly bothersome. A German study found the most commonly reported severe side effects of steroid therapy to be weight gain (48\%), moon face (46\%) and mood swings (36\%). Sixty-nine percent stated they would only take steroids if there was absolutely no other option and $17 \%$ would not consider taking further steroids. ${ }^{39}$ A second survey using a modified symptom distress scale found that 25 symptoms occurred more frequently in current corticosteroid users vs those who had never received steroids, although this resulted in significantly greater distress for only three symptoms (bruises, puffy face and excessive appetite). ${ }^{40} \mathrm{~A}$ third survey found a significant association between the duration of steroid treatment and both the number and severity of side effects. The most common side effects causing "a lot of bother" were moon face/bloating (68\%), weight gain/increased appetite (64\%), insomnia (46\%), anxiety (39\%), depression (37\%) and weakness/fatigue (35\%). They also found that treating physicians underestimated the negative impact of steroids on their patients..$^{30}$ Compared to patients receiving other treatments (IVIg, anti-D immunoglobulin, rituximab, splenectomy), those currently or previously receiving steroids had significantly more treatment side effects ( $98 \%, P<0.05)$, were more frequently severely bothered by side effects $(53 \%, P<0.05)$ and more frequently had to stop or reduce treatment $(38 \%, P<0.05){ }^{41}$

\section{TPO-RA: romiplostim}

In two Phase III randomized trials of romiplostim vs placebo, there was a statistically significant improvement in HRQoL for four out of ten (splenectomized) and one out of ten (nonsplenectomized) ITP-PAQ scales vs placebo over 24 weeks. $^{22}$ However, there was no application of the MID and mean change scores were not published numerically, so it is unclear whether these are clinically important differences. Fatigue symptoms did not improve with treatment. In a 52-week randomized open-label study of romiplostim vs standard of care in nonsplenectomized patients, statistically significant improvement from baseline occurred in nine out of ten scales for both arms, exceeding the MID in four out of seven assessable scales for standard of care and six out of seven for romiplostim. ${ }^{23}$ Although this improvement was statistically greater for patients receiving romiplostim in seven out of ten scales, none of these exceeded the MID, so the magnitude of the difference is of uncertain clinical benefit. As expected, the benefit seen in both arms was particularly pronounced in responders. There was no significant improvement in fatigue in either arm; however, for treatment responders in both arms, there was an improvement in fatigue from baseline that exceeded the MID.

\section{TPO-RA: eltrombopag}

In a 6-week study comparing eltrombopag to placebo, no significant differences in HRQoL were observed from baseline to the end of the study by the 36-Item Short Form Health Survey version 2 (SF-36v2). ${ }^{42}$ In the 6-month RAISE study of eltrombopag vs placebo, there was no significant improvement in fatigue by the FACIT-fatigue subscale. ${ }^{21}$ HRQoL by SF-36v2 did not improve in the placebo arm, but compared to placebo, those receiving eltrombopag had a statistically significant improvement in one out of two summary scores and three out of eight domains of the SF-36v2. However, there was no analysis of MID and none of the score differences were greater than 8 points, so it is unclear whether the difference is of clinical benefit. Efficacy and safety data from an open-label extension study of eltrombopag (EXTEND) have been published, ${ }^{43}$ but peer-reviewed data on HRQoL, which was a secondary endpoint (ClinicalTrials.gov identifier: NCT00351468), are currently awaited.

\section{Other treatments}

There is insufficient evidence to determine the impact of other treatments on HRQoL. In one survey, $73 \%-78 \%$ of patients who had received IVIg, anti-D or rituximab, or had undergone 
splenectomy, reported at least one side effect, $9 \%-11 \%$ were highly bothered by a treatment side effect, and for the three medical therapies $16 \%-21 \%$ had to stop or reduce treatment owing to side effects. ${ }^{41}$ In a 6-month randomized controlled trial of rituximab vs placebo, no treatment effect was found for change in HRQoL, assessed by SF-36. ${ }^{44}$ In another study, 16 patients in the standard of care arm had HRQoL assessed before and after rituximab, with no significant differences in ITP-PAQ scores. ${ }^{23}$ The same study also found no difference in ITP-PAQ before and after splenectomy in 13 patients. Another found that a prior history of splenectomy was not associated with a greater risk of significant fatigue. ${ }^{35}$ The observation of worse HRQoL in patients with a prior history of splenectomy vs those with no splenectomy ${ }^{19,22}$ may reflect disease severity and does not necessarily demonstrate causality. Furthermore, another study found that successful splenectomy markedly improved general health (34 splenectomized patients, $P<0.001) .{ }^{31}$ The same study of 111 adults with chronic ITP found that in multivariate analysis, the strongest predictors of HRQoL as measured by total SF-36 score were not treatment or platelet count, but rather bleeding episodes, comorbidities, employment and level of education. This highlights potential confounding variables and the importance of a control arm when measuring the impact of therapeutic agents on HRQoL.

\section{HRQoL in children with ITP}

The generic HRQoL measure most often applied to children with ITP is the PedsQL, usually as a comparator for the validation and reliability testing of an ITP-specific measure, the KIT. Another less frequently applied generic measure is "KINDL"45 and a second ITP-specific measure, the ITP-QoL, is being developed ${ }^{46,47}$ but is not yet widely used.

Using the generic PedsQL measure, no significant difference in HRQoL was found between newly diagnosed ITP patients and the normal French ${ }^{48}$ and Dutch ${ }^{28}$ reference populations. This observation may reflect the absence of ITPspecific HRQoL questions, and relatively unaffected scores in general HRQoL questionnaires have been observed in other hematological disorders such as hemophilia A. ${ }^{28}$

The KIT questionnaire consists of 26 questions that are aggregated into a single overall score ranging from 0 (worst) to 100 (best) and has a self-report version for children 7 years or older, a parent-proxy version for children as young as 2 years and a parent-impact version. The reliability and validity of cross-culturally translated versions of KIT have been demonstrated in various countries, including the UK, France, Germany and Uruguay. ${ }^{45}$ The MID has been estimated as 9-13 points for the child self-report version and 11-13 points for the parent-impact version..$^{49}$ Low KIT scores have been demonstrated in newly diagnosed patients, for example, a median 65 for child self-report and median 26 for parent impact. ${ }^{32}$ In this longitudinal study, HRQoL was significantly improved for patients and parents after 12 months $(P<0.001)$. This is perhaps unsurprising given the natural history of childhood ITP and, in this study, only $29 \%$ of assessable patients had ongoing ITP after 12 months. Indeed, at 12 months, HRQoL was significantly worse for those with persistent vs resolved ITP by child self-report (median 78 vs 97) and parent impact (median 30 vs 68). A second longitudinal study also found significantly worse HRQoL in children with persistent ITP vs those who recovered at 6 months, by parent proxy and parent impact (but not child self-report). ${ }^{28}$ Cross-sectional studies found better HRQoL in patients with chronic ITP vs newly presenting patients, ${ }^{45,50-52}$ suggesting that improvement with time is not only due to resolution of the disease.

The impact on HRQoL of platelet count, bleeding score and treatment has also been assessed. A lower platelet count was associated with worse HRQoL in some ${ }^{15,32}$ but not all ${ }^{53}$ studies using KIT assessment. This association is consistent with the finding that children with persistent disease have lower HRQoL. Differences may relate to sample size, statistical methodology or the strength of the association. Bleeding scores have not been found to have a negative impact on HRQoL, ${ }^{28,32,48,50,53}$ although in one study, higher grades of oral bleeding at diagnosis negatively impacted parent-proxy scores. ${ }^{32}$ The authors speculated that parents may perceive hemorrhagic vesicles as painful or make drinking or chewing difficult. In most studies, treatment intervention did not improve HRQoL, ${ }^{28,48,50}$ possibly because of side effects and greater inconvenience. Studies of the TPO-RAs romiplostim and eltrombopag did not report HRQoL improvement in treated patients compared to placebo. ${ }^{49,54,55}$ A reduced parental burden compared to placebo was found in romiplostim studies, ${ }^{49,55}$ but the difference was not significant in a meta-analysis. ${ }^{56}$

One strength of pediatric compared to adult HRQoL studies is that they capture the burden of illness in immediate next of kin through evaluation of parents' HRQoL. This burden is significant, with mean parent-impact KIT scores being lower than child self-report scores. ${ }^{15,28,32,57}$ For example, in 99 newly diagnosed children with ITP at baseline, the mean KIT score was 26 in parents, compared to 69 in children by parent-proxy and 65 by child self-assessment. ${ }^{32}$ Parental assessment has also shown that children and their parents perceive the disease differently. Parents' greatest concerns for their children were centered on fear of bleeding and injury, as 
well as uncertainty over the future clinical course. Children were most concerned about hospital visits, blood tests and restriction of participation in activities. ${ }^{28,57}$

\section{Discussion and future prospects}

Good medical care should aim to minimize the negative impact of ITP on HRQoL. Progress toward that goal has been made through the development of validated disease-specific HRQoL measures that can be used to assess the impact of interventions. Further progress could be made in two ways: first, through improvement in the overall standard of care for these patients and second, by seeking to identify patients with significantly reduced HRQoL and intervening where a specific issue has been identified.

\section{Improving the standard of care: nontherapeutic interventions}

The concerns of children with ITP differ from those of their parents and adults with ITP, such that supportive interventions should be age appropriate in their focus as well as delivery style. For children, this might involve minimizing hospital visits and blood tests where possible. In addition, overly cautious advice on activity restriction should be avoided, either through clinical networks that ensure that children with ITP are treated by clinicians with experience of the disorder and/ or through expert consensus recommendations on best practice. Further studies to better understand bleeding risk with sporting or other activities and better tests to define individual bleeding risk may also be useful. Adults could be supported by providing adequate verbal and written information on the disorder, including contact details for the clinical service and any local patient support groups. Fear of bleeding could be managed by providing a balanced view of bleeding risk.

\section{Improving the standard of care: therapeutic interventions}

Since HRQoL has been shown to improve following successful treatment, ${ }^{23}$ further HRQoL gain is likely with better tolerated and more effective treatments. These can be assessed using a validated HRQoL measure and the inclusion of a control arm.

HRQoL appears to deteriorate in the first year after diagnosis and so introducing effective new agents earlier in the treatment pathway has greater potential to prevent this decline. Furthermore, prevention may be preferable to attempting the resolution of adverse HRQoL because, once established, symptoms such as fatigue can persist despite successful treatment of the precipitating cause. For example, in a longitudinal study of 763 disease-free breast carcinoma survivors, $21 \%$ reported persistent problems with fatigue $5-10$ years after diagnosis. ${ }^{58}$ Steroids alone as a single firstline agent have a high relapse rate and significant adverse symptoms that do not resolve immediately on cessation. ${ }^{40}$ Hence, clinical trials of alternative first line regimens may lead to improved HRQoL.

\section{Assessing and managing HRQoL in routine practice}

In one study, most physicians asked their patients about bleeding symptoms but fewer enquired about HRQoL and the minority (39\%) asked about difficulty with sleep. ${ }^{59} \mathrm{~A}$ new direction for HRQoL tools in patients with ITP could be their integration into routine practice to identify clinically significant levels of distress. For example, the Hospital Anxiety and Depression Scale performs well in medical outpatients, primary care and the general population to detect those who would benefit from formal assessment for these disorders, using a cutoff of 8 or more in the anxiety and depression scales. ${ }^{60}$ A Fatigue Impact Scale score $\geq 40$ (2 SDs above the general population mean) has been used to define the presence of fatigue. ${ }^{35}$ Short screening tools have also been developed and validated in ambulatory cancer patients, for example, for the detection of clinically significant fatigue, pain, distress and anorexia. ${ }^{61}$

If significant adverse $\mathrm{HRQOL}$ is detected, intervention would depend on which symptoms are present and what the underlying cause, or causes, may be; for example, modifying drug regimens in response to side effects or treating iron deficiency in fatigued patients. The approach to social or work limitations will also depend on the root cause. For example, activity restriction and/or social embarrassment due to thrombocytopenia, bruising and fear of bleeding may favor a therapeutic intervention with a high response rate (eg, splenectomy, TPO-RA) over alternative medical therapies. In contrast, work and social limitations caused by frequent hospital attendance and treatment side effects may respond to a treatment switch or discontinuation and a watch-and-wait strategy. HRQoL is important to patients; for example, fatigue is consistently identified by those with rheumatoid arthritis as one of their top outcome priorities. ${ }^{62}$ We also know that adults with chronic ITP are willing to accept significant risks of adverse events in return for an increase in the probability of avoiding corticosteroids or for more convenient drug administration. ${ }^{63}$ Hence, HRQoL and patients' benefit-risk preferences need to be considered during discussion of therapeutic options. 
Adverse HRQoL may also respond to symptom-directed interventions. Although not explored in ITP patients, nonpharmacological interventions for fatigue have shown benefit in other disorders; for example, mindfulness-based training, cognitive behavioral therapy (CBT) and supervised exercise programs for people with multiple sclerosis. ${ }^{64}$ Similarly, fatigued cancer patients have benefited from physical activity programs, energy conservation, psychosocial support (eg, CBT), and sleep or complementary therapies. ${ }^{65}$ Although fatigue-directed pharmacological agents (eg, melatonin, amantadine) have been tried in other conditions, none has been studied in patients with ITP.

\section{Conclusion}

In summary, HRQoL tools have shown that ITP has a negative impact in multiple domains. They also show that this is not a static process, and HRQoL typically worsens in adults over the first year following diagnosis but then improves. Better HRQoL has also been observed in children with chronic ITP compared to newly presenting patients. HRQoL is improved in adults who respond to treatment and children who recover from their disease. Children experience their condition differently and HRQoL benefits have not been seen with treatment, possibly owing to its inconvenience. HRQoL tools should be used in trials and have potential "real-world" application in identifying morbidities that could inform disease- or symptom-directed interventions.

\section{Author contributions}

Both authors contributed to data analysis, drafting or revising the article, gave final approval of the version to be published, and agree to be accountable for all aspects of the work.

\section{Disclosure}

PT has no competing interests. QAH has received speaker and advisory fees from Novartis and research support from the ITP Support Association. The authors report no other conflicts of interest in this work.

\section{References}

1. Rodeghiero F, Stasi R, Gernsheimer T, et al. Standardization of terminology, definitions and outcome criteria in immune thrombocytopenic purpura of adults and children: report from an international working group. Blood. 2009;113(11):2386-2393.

2. Provan D, Stasi R, Newland AC, et al. International consensus report on the investigation and management of primary immune thrombocytopenia. Blood. 2010;115(2):168-186.

3. Hill QA. Immune thrombocytopenia - in defence of the platelet count. Br J Haematol. 2018;182(1):128-130.

4. Schoonen WM, Kucera G, Coalson J, et al. Epidemiology of immune thrombocytopenic purpura in the General Practice Research Database. Br J Haematol. 2009; 145(2):235-244.
5. George JN, Woolf SH, Raskob GE, et al. Idiopathic thrombocytopenic purpura: a practice guideline developed by explicit methods for the American Society of Hematology. Blood. 1996;88(1):3-40.

6. Yong M, Schoonen WM, Li L, et al. Epidemiology of paediatric immune thrombocytopenia in the General Practice Research Database. $\mathrm{Br} J$ Haematol. 2010;149(6):855-864.

7. Cooper N. State of the art- how I manage immune thrombocytopenia. Br J Haematol. 2017;177(1):39-54.

8. Nørgaard M, Jensen AØ, Engebjerg MC, et al. Long-term clinical outcomes of patients with primary chronic immune thrombocytopenia: a Danish population-based cohort study. Blood. 2011;117(13):3514-3520.

9. Portielje JE, Westendorp RG, Kluin-Nelemans HC, Brand A. Morbidity and mortality in adults with idiopathic thrombocytopenic purpura. Blood. 2001;97(9):2549-2554.

10. Kirsch M, Klaassen RJ, de Geest S, Matzdorff A, Ionova T, Dobbels F. Understanding the importance of using patient-reported outcome measures in patients with immune thrombocytopenia. Semin Hematol. 2013;50(Suppl 1):S39-S42.

11. Stasi R, Newland AC. ITP: a historical perspective. Br J Haematol. 2011;153(4):437-450.

12. Barnard D, Woloski M, Feeny D, et al. Development of disease-specific health-related quality-of-life instruments for children with immune thrombocytopenic purpura and their parents. J Pediatr Hematol Oncol. 2003;25(1):56-62.

13. Klaassen RJ, Young NL. Health-related quality of life outcomes for patients with immune thrombocytopenic purpura. Ann Hematol. 2010;89(Suppl 1):51-54.

14. Mathias SD, Gao SK, Rutstein M, Snyder CF, Wu AW, Cella D. Evaluating clinically meaningful change on the ITP-PAQ: preliminary estimates of minimal important differences. Curr Med Res Opin. 2009;25(2):375-383.

15. Zhang H, Wang L, Quan M, et al. Health-related quality of life in children with chronic immune thrombocytopenia in China. Health Qual Life Outcomes. 2016;14:45.

16. Efficace F, Mandelli F, Fazi P, et al. Health-related quality of life and burden of fatigue in patients with primary immune thrombocytopenia by phase of disease. Am J Hematol. 2016;91(10):995-1001.

17. Zhou Z, Yang L, Chen Z, et al. Health-related quality of life measured by the Short Form 36 in immune thrombocytopenic purpura: a crosssectional survey in China. Eur J Haematol. 2007;78(6):518-523.

18. McMillan R, Bussel JB, George JN, Lalla D, Nichol JL. Self-reported health-related quality of life in adults with chronic immune thrombocytopenic purpura. Am J Hematol. 2008;83(2):150-154.

19. Snyder CF, Mathias SD, Cella D, Isitt JJ, Wu AW, Young J. Health-related quality of life of immune thrombocytopenic purpura patients: results from a web-based survey. Curr Med Res Opin. 2008;24(10):2767-2776.

20. Löfling L, Linder M, Ekstrand C, Cherif H, Kieler H, Bahmanyar S. Pharmacological agents preceding a diagnosis of immune thrombocytopenia in adult patients developing the chronic form: a Swedish national register study. Thromb Res. 2017;160:27-31.

21. Cheng G, Saleh MN, Marcher C, et al. Eltrombopag for management of chronic immune thrombocytopenia (RAISE): a 6-month, randomised, phase 3 study. Lancet. 2011;377(9763):393-402.

22. George JN, Mathias SD, Go RS, et al. Improved quality of life for romiplostim-treated patients with chronic immune thrombocytopenic purpura: results from two randomized, placebo-controlled trials. $\mathrm{Br} J$ Haematol. 2009;144(3):409-415.

23. Kuter DJ, Mathias SD, Rummel M, et al. Health-related quality of life in nonsplenectomized immune thrombocytopenia patients receiving romiplostim or medical standard of care. Am J Hematol. 2012;87(5):558-561.

24. Mathias SD, Bussel JB, George JN, McMillan R, Okano GJ, Nichol JL. A disease-specific measure of health-related quality of life for use in adults with immune thrombocytopenic purpura: its development and validation. Health Qual Life Outcomes. 2007;5:11.

25. Mathias SD, Bussel JB, George JN, McMillan R, Okano GJ, Nichol JL. A disease-specific measure of health-related quality of life in adults with chronic immune thrombocytopenic purpura: psychometric testing in an open-label clinical trial. Clin Ther. 2007;29(5):950-962. 
26. Mathias SD, Gao SK, Miller KL, et al. Impact of chronic Immune Thrombocytopenic Purpura (ITP) on health-related quality of life: a conceptual model starting with the patient perspective. Health Qual Life Outcomes. 2008;6:13.

27. Sarpatwari A, Watson S, Erqou S, et al. Health-related lifestyle in adults and children with primary immune thrombocytopenia (ITP). $\mathrm{Br}$ J Haematol. 2010;151(2):189-191.

28. Heitink-Pollé KM, Haverman L, Annink KV, Schep SJ, de Haas M, Bruin MC. Health-related quality of life in children with newly diagnosed immune thrombocytopenia. Haematologica. 2014;99(9): 1525-1531.

29. Kumar M, Lambert MP, Breakey V, et al. Sports Participation in Children and Adolescents with Immune Thrombocytopenia (ITP). Pediatr Blood Cancer. 2015;62(12):2223-2225.

30. Guidry JA, George JN, Vesely SK, Kennison SM, Terrell DR. Corticosteroid side-effects and risk for bleeding in immune thrombocytopenic purpura: patient and hematologist perspectives. Eur J Haematol. 2009;83(3):175-182.

31. Suvajdzic N, Zivkovic R, Djunic I, et al. Health-related quality of life in adult patients with chronic immune thrombocytopenia in Serbia. Platelets. 2014;25(6):467-469.

32. Flores A, Klaassen RJ, Buchanan GR, Neunert CE. Patterns and influences in health-related quality of life in children with immune thrombocytopenia: a study from the Dallas ITP cohort. Pediatr Blood Cancer. 2017;64(8):e26405.

33. Tarantino MD, Mathias SD, Snyder CF, Isitt JJ, Gernsheimer T, Young J. Impact of ITP on physician visits and workplace productivity. Curr Med Res Opin. 2010;26(2):319-328.

34. Blatt J, Weston B, Gold S. Fatigue as marker of thrombocytopenia in childhood idiopathic thrombocytopenic purpura. Pediatr Hematol Oncol. 2010;27(1):65-67.

35. Newton JL, Reese JA, Watson SI, et al. Fatigue in adult patients with primary immune thrombocytopenia. Eur J Haematol. 2011;86(5):420-429.

36. Tsukune Y, Komatsu N. Management of Adult Chronic Immune Thrombocytopenia in Japan: Patient and Hematologist Perspectives from a Multi-center Cross-sectional Questionnaire Survey. Intern Med. 2016;55(17):2379-2385.

37. Hill QA, Newland AC. Fatigue in immune thrombocytopenia. $\mathrm{Br} J$ Haematol. 2015;170(2):141-149.

38. Enns MW, Bernstein CN, Kroeker K, et al. The association of fatigue, pain, depression and anxiety with work and activity impairment in immune mediated inflammatory diseases. PLoS One. 2018;13(6): 0198975.

39. Matzdorff AC, Arnold G, Salama A, Ostermann H, Eberle S, Hummler S. Advances in ITP - therapy and quality of life - a patient survey. PLoS One. 2011;6(11):e27350.

40. Berti D, Moons P, Dobbels F, Deuson R, Janssens A, de Geest S. Impact of corticosteroid-related symptoms in patients with immune thrombocytopenic purpura: results of a survey of 985 patients. Clin Ther. 2008;30(8):1540-1552.

41. Brown TM, Horblyuk RV, Grotzinger KM, Matzdorff AC, Pashos CL. Patient-reported treatment burden of chronic immune thrombocytopenia therapies. BMC Blood Disord. 2012;12(2):2.

42. Bussel JB, Cheng G, Saleh MN, et al. Eltrombopag for the treatment of chronic idiopathic thrombocytopenic purpura. $N$ Engl J Med. 2007;357(22):2237-2247.

43. Wong RSM, Saleh MN, Khelif A, et al. Safety and efficacy of long-term treatment of chronic/persistent ITP with eltrombopag: final results of the EXTEND study. Blood. 2017;130(23):2527-2536.

44. Arnold DM, Heddle NM, Carruthers J, et al. A pilot randomized trial of adjuvant rituximab or placebo for nonsplenectomized patients with immune thrombocytopenia. Blood. 2012;119(6):1356-1362.

45. Klaassen RJ, Blanchette V, Burke TA, et al. Quality of life in childhood immune thrombocytopenia: international validation of the kids' ITP tools. Pediatr Blood Cancer. 2013;60(1):95-100.
46. Giordano P, Lassandro G, Giona F, et al. ITP-QoL questionnaire for children with immune thrombocytopenia: Italian version validation's. Pediatr Hematol Oncol. 2014;31(6):534-547.

47. von Mackensen S, Nilsson C, Jankovic M, et al. Development of a disease-specific quality of life questionnaire for children $\&$ adolescents with idiopathic thrombocytopenic purpura (ITP-QoL). Pediatr Blood Cancer. 2006;47(5 Suppl):688-691.

48. Strullu M, Rakotonjanahary J, Tarral E, et al. Evaluation of health related quality of life in children with immune thrombocytopenia with the PedsQL ${ }^{\text {TM }} 4.0$ Generic Core Scales: a study on behalf of the pays de Loire pediatric hematology network. Health Qual Life Outcomes. 2013;11:193.

49. Mathias SD, Li X, Eisen M, Carpenter N, Crosby RD, Blanchette VS. A Phase 3, randomized, double-blind, placebo-controlled study to determine the effect of Romiplostim on health-related quality of life in children with primary immune thrombocytopenia and associated burden in their parents. Pediatr Blood Cancer. 2016;63(7): 1232-1237.

50. Grainger JD, Young NL, Blanchette VS, Klaassen RJ. Quality of life in immune thrombocytopenia following treatment. Arch Dis Child. 2013;98(11):895-897.

51. Klaassen RJ, Blanchette VS, Barnard D, et al. Validity, reliability, and responsiveness of a new measure of health-related quality of life in children with immune thrombocytopenic purpura: the kids' ITP tools. J Pediatr. 2007;150(5):510-515.e1.

52. Mokhtar GM, Farid SM, Shaker NM, Farrag KE. Health-related quality of life of Egyptian children with immune thrombocytopenia and their parents. J Pediatr Hematol Oncol. 2014;36(3):194-199.

53. Neunert CE, Buchanan GR, Blanchette V, et al. Relationships among bleeding severity, health-related quality of life, and platelet count in children with immune thrombocytopenic purpura. Pediatr Blood Cancer. 2009;53(4):652-654.

54. Bussel JB, de Miguel PG, Despotovic JM, et al. Eltrombopag for the treatment of children with persistent and chronic immune thrombocytopenia (PETIT): a randomised, multicentre, placebo-controlled study. Lancet Haematol. 2015;2(8):e315-e325.

55. Klaassen RJ, Mathias SD, Buchanan G, et al. Pilot study of the effect of romiplostim on child health-related quality of life (HRQoL) and parental burden in immune thrombocytopenia (ITP). Pediatr Blood Cancer. 2012;58(3):395-398.

56. Guo JC, Zheng Y, Chen HT, et al. Efficacy and safety of thrombopoietin receptor agonists in children with chronic immune thrombocytopenia: a meta-analysis. Oncotarget. 2018;9(6):7112-7125.

57. Zilber R, Bortz AP, Yacobovich J, Yaniv I, Tamary H. Analysis of health-related quality of life in children with immune thrombocytopenia and their parents using the kids' ITP tools. J Pediatr Hematol Oncol. 2012;34(1):2-5.

58. Bower JE, Ganz PA, Desmond KA, et al. Fatigue in long-term breast carcinoma survivors: a longitudinal investigation. Cancer. 2006;106(4):751-758.

59. Rabin DU, Kuter DJ, Liebman HA, Bussel JB. What do healthcare providers ask their patients with immune thrombocytopenia? Am J Hematol. 2010;85(8):629-631.

60. Bjelland I, Dahl AA, Haug TT, Neckelmann D. The validity of the Hospital Anxiety and Depression Scale. An updated literature review. J Psychosom Res. 2002;52(2):69-77.

61. Butt Z, Wagner LI, Beaumont JL, et al. Use of a single-item screening tool to detect clinically significant fatigue, pain, distress, and anorexia in ambulatory cancer practice. J Pain Symptom Manage. 2008;35(1):20-30.

62. Hewlett S, Chalder T, Choy E, et al. Fatigue in rheumatoid arthritis: time for a conceptual model. Rheumatology. 2011;50(6):1004-1006.

63. Hauber AB, Johnson FR, Grotzinger KM, Ozdemir S. Patients' benefitrisk preferences for chronic idiopathic thrombocytopenic purpura therapies. Ann Pharmacother. 2010;44(3):479-488. 
64. National Institute for Health and Care Excellence. Clinical Guideline [CG186]. Multiple Sclerosis in Adults: Management. London: NICE; 2014. Available from: https://www.nice.org.uk/guidance/cg186. Accessed November 5, 2018.

65. Koornstra RH, Peters M, Donofrio S, van den Borne B, de Jong FA. Management of fatigue in patients with cancer-a practical overview. Cancer Treat Rev. 2014;40(6):791-799.
66. Signorovitch J, Brainsky A, Grotzinger KM. Validation of the FACITfatigue subscale, selected items from FACT-thrombocytopenia, and the SF-36v2 in patients with chronic immune thrombocytopenia. Qual Life Res. 2011;20(10):1737-1744.

\section{Publish your work in this journal}

Patient Related Outcome Measures is an international, peer-reviewed, open access journal focusing on treatment outcomes specifically relevant to patients. All aspects of patient care are addressed within the journal and practitioners from all disciplines are invited to submit their work as well as healthcare researchers and patient support groups.
The journal is included in PubMed. The manuscript management system is completely online and includes a very quick and fair peer-review system. Visit http://www.dovepress.com/testimonials.php to read real quotes from published authors. 